\title{
Bibliogratía hispanoamericana de Federico García Lorca
}

\section{EDICIONES}

I. Obras completas de Federico Garcia Lorca, (seis tomos), Editorial Losada, Buenos Aires, I938. (I)

Tomo I.-Bodas de sangre; Amor de don Perlimplin con Belisa en su jardín; Retablillo de don Cristóbal. Estudio preliminar por Guillermo de Torre.

Tono II.-Libro de poemas; Primeras canciones; Canciones; Seis poemas gallegos. Introducción a los poemas gallegos por Eduardo Blanco Amor.

Tomo III.-Yerma; La sapatera prodigiosa.

Tomo IV.-Romancero gitano; Poema del cante jondo; Llanto por Ignacio Sánchez Mejias.

Tomo V.-Doña Rosita la soltera o el lenguaje de las flores; Mariana Pineda.

Tomo VI-Asi que pasen cinco años; Poemas póstumos; El público; El poeta en Nueva York; El diván de Tamarit; Seis canciones musicales. (Advertencias del recopilador, Guillermo de Torre; indicación de fuentes, y bibliografia esencial). (2)

2. Canciones (1921-1924), Santiago de Chile, Editorial Moderna, s. a. (probablemente 1937). Segunda edición.

3. Romancero gitano (I924-1927), tercera edición, Buenos Aires, Sur, I933.

Moderna, s. a. (probablemente I936).

sa-Calpe, 1937. Inipreso en Buenos Aires. 
, Santiago de Chile, s. e., 1937.

, Buenos Aires, Editorial Argentores, s. e., 1937.

Aparece en el mismo folleto con Mariana Pineda.

4. Poema del cante jondo, (I92I), Madrid y Buenos Aires, Compañía Iberoamericana de Publicaciones, 1931. (S. e.; pero es la primera edición).

- Santiago de Chile, Editorial Veloz, s. a. y s. e. (Probablemente 1937). Contiene Federico Garcia Lorca retratado por Pablo Neruda; poemas sobre la muerte del poeta por Antonio Machado, Carlos L. Sáenz, y Pablo Neruda; y García Lorca en Montevideo por Alfredo María Ferreiro. (Faltan varias páginas del ensayo de Ferreiro).

5. Un poema de Federico García Lorca, México, Alcancía, 1933. En el frontis aparece el título del poema: Oda a Walt Whitman. "Se tiraron cincuenta ejemplares numerados del I al 50 fuera de comercio". Edición ilustrada por Manuel Rodríguez Lozano.

6. Llanto por Ignacio Sánches Mejias, aparece en el mismo tomo con Yerma, poema trágico en tres actos en prosa y en verso. Lima, Editorial Latina, s. a., (probablemente 1937). Segunda edición corregida por José López Garmendia.

7. Mariana Pineda, romance popular en tres estampas. (y)

Romancero gitano, (en el mismo folleto), Editorial Argentores, Buenos Airts, I937.

Mariana Pineda, Santiago de Chile, Editorial Moderna, s. a.

8. Bodas de sangre, tragedia en 3 actos y 7 cwadros, Buenos Aires, Éditorial Teatro del Pueblo, 1936.

, Santiago de Chile, Editorial Moderna, s. a.

9. Yerma, poema trágico en tres actos, Santiago de Chile, Editorial Iberia, s. a.

Editorial Latina, s. a. Segunda edición corregida por José López Garmendia.

\section{ANTOLOGIAS}

I. Federico García Lorca, Breve antología, poemas seleccionados y presentados por Juan Marinello, México, L.E.A.R., 1936. Marinello presentó estos poemas en un homenaje a García Lorca en el $\mathrm{Pa}$ lacio de Bellas Artes el I4 de noviembre de 1936. Contiene un 
estudio preliminar del recopilador. Selección bien hecha. 44 páginas; 34 páginas de poesías.

2. Federico García Lorca, antología, selección y prólogo de María Zam- brano, segunda edición, Santiago de Chile, Editorial Panorama, 1937. Contiene también poemas en la muerte del poeta por Antonio Machado, Rafael Alberti y Pablo Neruda. María Zambrano compara a Lorca con Juan Ramón Jiménez y Antonio Machado; llama la poesía de Lorca "regreso a la sangre y a la muerte". 78 páginas: sin índice.

3. Antología poética de Federico García Lorca, selección, prólogo y notas de Norberto Pinilla, Santiago de Chile, Zig-Zag, s. a. (probablemente 1937). Contiene 218 páginas; 8 de índice. Selección bien hecha, no sólo de las poesías del poeta, sino también de varios pasajes de sus dramas. (A nuestro ver la mejor de las antologías).

4. Antologia selecta de Federico García Lorca, homenaje en el primer aniversario de su nuerte, Buenos Aires, Editorial Teatro del Pucblo, 1937. Contiene 95 páginas y una de indice. Hay un ensayo (el ensayo de siempre) por Pablo Neruda, y poemas a Lorca por Alfonso Reyes, Pablo Suero, E. Navas, Rafael Alberti, Antonio Machado, J. Gómez Bas, H. R. Klappenbach, Carlos Luis Sáenz y Pablo Neruda. (3)

III. REVISTAS HISPANOAMERICANAS QUE HAN OFRECIDO NUMEROS DE HOMENAJE A GARCIA LORCA

I. SECH, Revista de la Sociedad de Escritores de Chile, Santiago, núm. 3, diciembre de 1936. Contiene tres poemas de García Lorca: Nocturno del hueco; Romance de la luna, luna; fragmentos de la Muerte de Antoñito el Camborio. Hay también un breve ensayo de Juvencio Valle, y pocmas a Lorca por Pablo Neruda y Carlos Luis Sáenz.

2. Revista de las Indias, marzo de 1937 , Bogotá. Contiene 26 poemas de García Lorca; una nuta bibliográfica de Jorge Zalamea, poemas a Lorca por Darío Samper, Eduardo Carranza, Antonio Machado y Manuel Altolaguirre, y estudios sebre casi todas las fases del poeta por Rafael Maya, Lino Gil Jaramillo, Eduardo Zalamea Borda, Dario Achury Valenzuela, G. Castañeda Aragón, Ráúl Roa, Eduardo Blanco-Amor, Melchor Fernández Almagro y Gerardo Diego.

3. Revistá de la Universidad de Panamá, Pananá, agosto de I937. Con- 
tiene poemas en la muerte de García Lorca por Dario Samper, Antonio Machado, Luis Amado Blanco, Rogelio Sinán, Eda Nela, Rodrigo Miró; ensayos de Pablo Neruda, Gerardo Diego, Fernández Almagro, Castañeda Aragón, Baltasar Isaza Calderón, Rafael Maya y Darío Achury Valenzuela, tomados en su mayor parte de la arriba mencionada Revista de las Indias. Hay también 13 breves selecciones de cuatro obras del poeta.

4. Repertorio Americano, San José de Costa Rica, 18 de diciembre de 1937. Aunque este número no lleva las palabras homenaje a Garcia Lorca expresa esencialmente tal homenaje. Contiene selecciones del poeta (Romance de la guardia civil española, y una escena inédita del drama Asi que pasen cinco años), la Cantata en la tumba de -Federico García Lorca por Alfonso Reyes, y un cxcclente ensayo sobre la muerte del poeta por Vicente Sáenz, titulado Consideraciones sobre civilización occidental a propósito de Federico Garcia Lorca.

\section{ESTUDIOS Y HOMENAJES APARECIDOS EN LIBROS}

I. Homenaje de escritores y artistas a García Lorca. Organizado por Norberto A. Frontini con ocasión de los recitales de Mony Hermelo. (Poemas y prosas de Alfonso Reyes, Carlos Mastronardi, Conrado Nalé Roxlo, González Carbalho, César Tiempo, Amado Villar, Pondal Ríos, Ricardo E. Molinari, Raúl González Tuñón, Nicolás Olivari, Eduardo Blanco-Amor, Pablo Suero, Jesualdo, Santiago Ganduglia y José Portogalo). Buenos Aires, Montevideo (s. e.), 1937.

2. Federico García Lorca por Hugo Moncayo. (Conferencia). Grupo América. Quito; Ecuador; Imprenta de la Universidad Central, 1937.

3. Federico García Lorca a través de Margarita Xirgu por Arturo Aldunate Philips. (Ensayo leído en la Universidad de Chile). Ed. Nascimento, Santiago de Chile, I937.

4. Poema desesperado (A la muerte de Federico García Lorca) por Luis Amado Blanco. Ed. Ucacia, San Cristóbal de la Habana, 1937.

5. Centinela de la sangre (Federico García Lorca) por José Portogalo, (s. e.), Buenos Aires, 1937 .

6. Vida, obra y muerte de Federico García Lorca por González Carbalho (escrita para ser leída en un acto recordatorio), Ed. Ercilla, Santiago de Chile, I938. 
7. Presencias de teatro por Armando de Maria y Campos. (Crónicas 1934-1936). Ed. Botas, México, 1937. Contiene un estudio sobre el teatro de Lorca.

8. Teatro de hoy por Federico Orcajo Acuña. Ed. Sociedad Amigos del Libro Rioplatense, Montevideo-Buenos Aires, 1936. El primer estudio del libro versa sobre el teatro de García Lorca.

JoHN A. CRow,

Universidad de California, Los Angeles, California.

(1) - - El primer tomo lieva esta advertencia: "Esta edición ha sido hecha con la autorización debida y ha sido escrupulosamente revisada, de acuerdo con los originales de Federico García Lorca que tengo en mi poder y que contienen los últimos retoques del autor". Firmada, Margarita Xirgu, Buenos Aires; julio de 1938.

(2) - Esta edición de las Obras Completas omite el drama La casa de Bernarda Alba; El moleficio de la mariposa, primera obra dramática; y varias conferencias $y$ artíctlos del poeta. El recopilador dice que no ha podido valerse de los originales de El diván de Tamarit y El poeta en Nueva York. Las famosas odas del poeta aparecen en El diván de Tamarit.

(3).--En la Antología de poetas españoles contemporóneos, selecciones de J. M. Souvirón, Santiago de Chile, Nascimento, 1934, hay una sección nutrida dedicada a Lorca. 
